\title{
Philippe Forest, La beauté du contresens, Allaphbed I
}

\section{Gabriella Bosco}

\section{(2) OpenEdition}

\section{Journals}

\section{Edizione digitale}

URL: http://journals.openedition.org/studifrancesi/31066

DOI: 10.4000/studifrancesi.31066

ISSN: 2427-5856

\section{Editore}

Rosenberg \& Sellier

\section{Edizione cartacea}

Data di pubblicazione: 1 avril 2006

Paginazione: 220

ISSN: 0039-2944

\section{Notizia bibliografica digitale}

Gabriella Bosco, «Philippe Forest, La beauté du contresens, Allaphbed l», Studi Francesi [Online], 148 (XLX | I) | 2006, online dal 30 novembre 2015, consultato il 18 avril 2021. URL: http://

journals.openedition.org/studifrancesi/31066 ; DOI: https://doi.org/10.4000/studifrancesi.31066

\section{Questo documento è stato generato automaticamente il 18 avril 2021.}

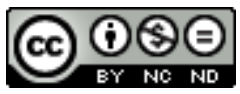

Studi Francesi è distribuita con Licenza Creative Commons Attribuzione - Non commerciale - Non opere derivate 4.0 Internazionale. 


\title{
Philippe Forest, La beauté du contresens, Allaphbed I
}

\author{
Gabriella Bosco
}

\section{NOTIZIA}

Philippe Forest, La beauté du contresens, Allaphbed I, Nantes, éditions Cécile Défaut, 2005, pp. 314.

1 Nel corso dell'ultimo decennio, Philippe FOREST ha messo a punto uno strumento critico di straordinaria efficacia, cui ha dato il nome di "roman du je". Studioso delle avanguardie novecentesche, dal surrealismo a Tel Quel al Nouveau Roman, aveva analizzato il fenomeno dell'ostracismo del soggetto narrativo e poi assistito al suo ritorno in forze nel romanzo contemporaneo, anche e soprattutto nelle opere di quegli stessi scrittori che sembravano averlo demonizzato. L'intelligenza critica di Forest gli ha permesso di dimostrare che l'ostracismo in questione era stato solo apparente. In realtà, ha spiegato Forest, si era trattato non di una "defenestrazione", come a lungo si era detto e creduto, bensì di una trasformazione del ruolo del soggetto narrativo, dell"'io" scrivente. La scrittura in prima persona in quanto autobiografia secondo le regole precise teorizzate da Philippe Lejeune è stata effettivamente criticata e disertata da parte dei protagonisti delle avanguardie novecentesche, ma non per il suo essere in prima persona. Bensì per la fiducia di cui era portatrice, che sia possibile riprodurre sulla pagina l'esperienza vissuta: l'autobiografia in quanto riproduzione, rappresentazione della propria vita attraverso le parole non convinceva più autori che avevano fondato la loro poetica sul rifiuto del realismo alla Balzac. A partire da questa intuizione, studiando i romanzi di Philippe Sollers, Alain Robbe-Grillet, Philip Roth, Kenzaburo Oe tra gli altri, Forest ha individuato la specificità del soggetto nella scrittura contemporanea, un soggetto in qualche modo "prodotto" dalla pagina, che nasce dalla scrittura, che diventa reale cioè nel momento in cui, attraverso la finzione, si oggettivizza. 
2 Da comparatista, formatosi alla scuola di Pierre Brunel, Forest sperimenta da tempo l'applicabilità della sua teoria alla letteratura giapponese. Curioso di una scrittura diversa, difficilmente interpretabile con criteri occidentali, Forest si è reso progressivamente conto che esistono analogie interessanti tra l'autobiografia occidentale e il watakushi shosetsu giapponese, e tra il romanzo dell'io quale lui lo intende e una certa scrittura in prima persona praticata dai romanzieri giapponesi contemporanei. In La beauté $d u$ contresens, primo volume di una serie in cui raccoglierà $\mathrm{i}$ suoi saggi giapponesi, Forest illustra i modi del suo approccio a quella letteratura, e teorizza una forma di comparatismo necessariamente "alternativa". La spiegazione che dà, all'inizio del libro, del titolo scelto, è molto chiara. Forest afferma di averlo tratto dal Contre Sainte-Beuve, celebre citazione del brano in cui il futuro autore della Recherche dichiara: "Les beaux livres sont écrits dans une sorte de langue étrangère. Sous chaque mot chacun de nous met son sens ou du moins son image qui est souvent un contresens. Mais dans les beaux livres, tous les contresens qu'on fait sont beaux". Spiega Forest che leggendo i romanzi giapponesi spesso ha la sensazione che siano scritti nella più straniera delle lingue, ma che la loro stessa estraneità diventa, paradossalmente, condizione di una conturbante prossimità, perché sotto ognuna di quelle parole estranee è offerta miracolosamente la libertà di insinuare il significato sbagliato, l'immagine erronea da cui nasce la chance di una nuova bellezza.

3 Forte di questo "paradosso critico", Forest affronta la lettura dei grandi nomi del romanzo giapponese contemporaneo (Kenzaburo Oe, Yukio Mishima, Dazaï Ozuma, ma anche Tsushima Yukô o Kenji Nakagami), spaziando da Rabelais a Céline, Sartre, Bataille o Quignard nell'affascinante esercizio del controsenso interpretativo. 